\title{
LOS DOCUMENTOS ELECTRÓNICOS Y SU VALOR PROBATORIO: EN PROCESOS DE CARÁCTER JUDICIAL
}

\author{
Deisy Yanet Acevedo Surmay \\ Maestría en Derecho Laboral (en curso), Universidad Externado de Colombia (Col); Especialista en Derecho \\ Procesal, en Seguridad Social, Universidad Santo Tomás, Bucaramanga (Col); Abogada Universidad Santo Tomás, \\ Bucaramanga (Col). Juez Tercero Laboral de Descongestión del Circuito Judicial de Bucaramanga (Col). \\ E-mail: dsurmay28@hotmail.com \\ Élber Enrique Gómez Ustaris \\ Maestría en Derecho Público (en curso), Universidad Santo Tomás, Bogotá D.C., (Col); Especialista en Derecho \\ Procesal, Derecho Administrativo, Contratación Estatal, Universidad Santo Tomás, Bucaramanga, (Col); \\ Especialista en Administración Pública Contemporánea, Derechos Humanos, Escuela de Administración Pública- \\ ESAP, Bogotá D. C; (Col), Especialista en Docencia Universitaria, Abogado, Universidad Cooperativa de \\ Colombia, Bucaramanga (Col); Asesor Juridico y Representante Legal-Asociación colombiana de Soldados \\ Discapacitados del Ejercito Nacional-ACOSDEN (Col). \\ E-mail.: elber84073297@gmail.com
}

\section{Resumen}

El tema de los documentos digitales o electrónicos como pruebas judiciales, ha tomado una relevante importancia en los últimos años debidos precisamente al auge de los medios de comunicación digitales y a los efectos de la globalización electrónica; esta importancia radica precisamente en el hecho de que muchas actividades comerciales y no comerciales que se realizan en la actualidad contemplan la utilización de dichas herramientas. El objetivo del presente trabajo es realizar un análisis de la normatividad colombiana en lo referente a la utilización de los documentos electrónicos como prueba dentro de los procesos judiciales que se han adelantado en el distrito judicial de Bucaramanga, y resaltar la importancia del conocimiento que deben tener los juzgadores en pruebas de carácter electrónico, al momento que acometen la tarea de fallar un caso cimentado en esta clase de pruebas.

Palabras Clave: Documentos Electrónicos. Pruebas Electrónicas. Funcionario Judicial. Proceso Judicial. Medios de prueba.

\begin{abstract}
The issue of digital or electronic documents as evidence in court, has taken a significant importance in recent years precisely due to the rise of digital media and electronic effects of globalization, the importance lies precisely in the fact that many activities commercial and noncommercial taking place at present contemplate the use of such tools. The aim of this study is to analyze the Colombian regulations regarding the use of electronic documents as evidence in legal proceedings that have been advanced in the judicial district of Bucaramanga, and highlight the importance of knowledge that must be the judges in any electronic evidence, when they undertake the task of missing a case founded on this kind of evidence.
\end{abstract}

Key Words: Electronic Documents. Electronic Evidence. Judicial Officer. Ev idence Judicial Process.

\begin{abstract}
Résumé
La question des documents numériques ou électroniques comme preuve devant un tribunal, a pris une importance considérable ces dernières années précisément en raison de la montée des médias numériques et les effets électroniques de la mondialisation, l'importance réside précisément dans le fait que de nombreuses activités commerciale et non commerciale aura lieu à l'heure actuelle envisager l'utilisation de ces outils. Le but de cette étude est d'analyser les réglementations colombiennes concernant l'utilisation des documents électroniques comme preuve dans les procédures judiciaires qui ont été avancés dans le district judiciaire de Bucaramanga, et soulignent l'importance de la connaissance qui doit être les juges dans tous les éléments de preuve électroniques, quand ils entreprennent la tâche de manquer une affaire fondée sur ce genre de preuve.
\end{abstract}

Mots-clés: Les documents électroniques. La preuve électronique. Huissier de justice. Processus judiciaire. Preuve. 

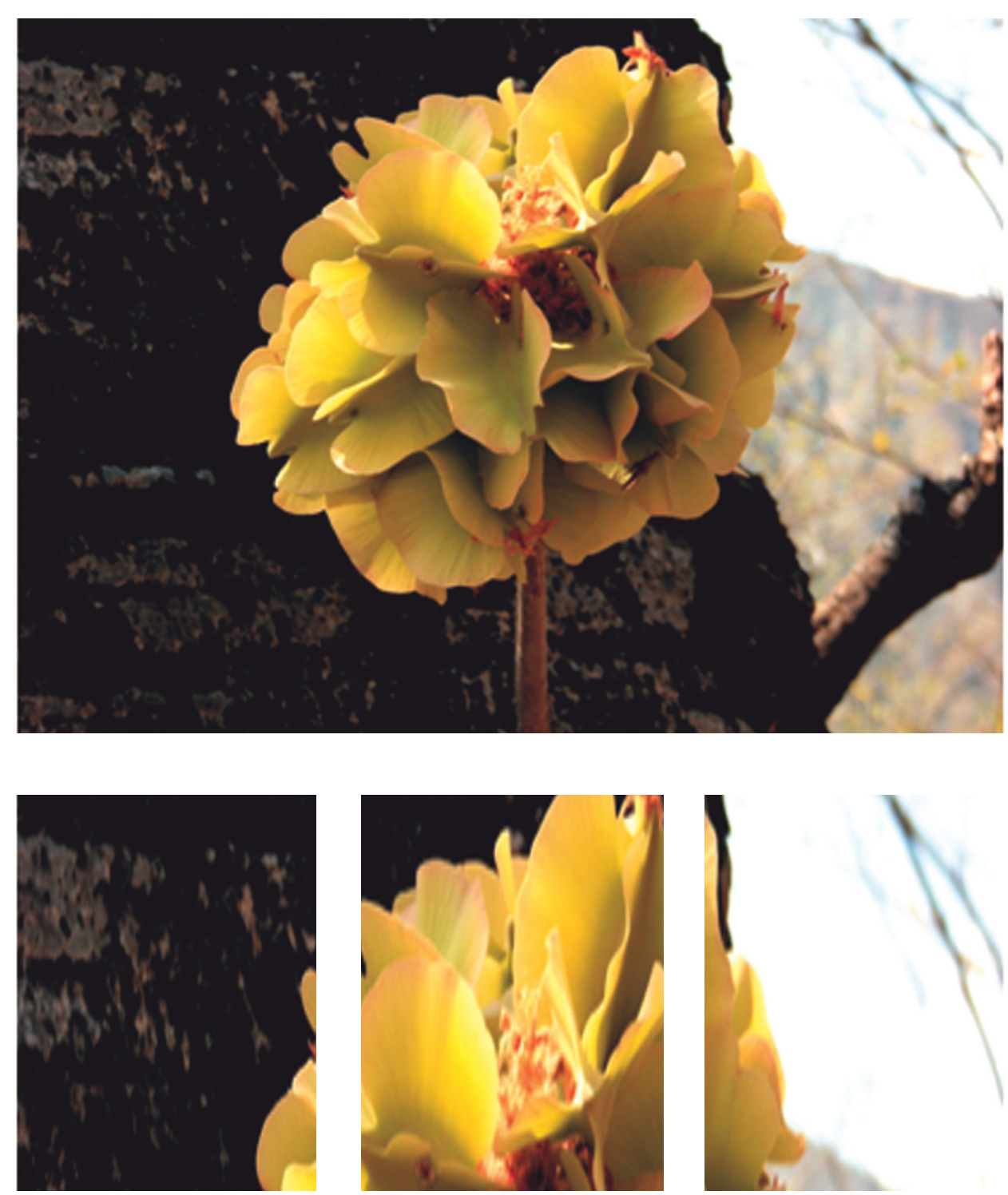

Cañón del Chicamocha - Ceibas Barrigonas

Jorge William Sánchez Latorre 


\section{LOS DOCUMENTOS ELECTRÓNICOS Y SU VALOR PROBATORIO: EN PROCESOS DE CARÁCTER JUDICIAL*}

Deisy Yanet Acevedo Surmay Élber Enrique Gómez Ustaris

En el contexto de un mundo globalizado en el que los medios de comunicación posibilitan la ruptura de las fronteras del tiempo y del espacio, la utilización de los medios electrónicos resulta fundamental, aspecto en el cual la ciencia jurídica no se ha podido sustraer, a tal punto que su utilización es, cada vez, más frecuente. Por esta razón, es claro que en el campo del derecho procesal disponer de este recurso como elemento probatorio enriquecerá el ejercicio profesional y pondrá la labor del juez a tono con el avance de la realidad social y tecnológica que impregna la realidad actual. Así, para tener éxito en el ejercicio jurídico y sacar adelante las demandas que se presenten en los procedimientos de carácter contencioso, es necesario que el juzgador sea capaz de valorar las pruebas electrónicas solicitadas y decretadas dentro del respectivo expediente judicial.

El tema de los documentos digitales como pruebas judiciales ha tomado una relevante importancia en los últimos años debido precisamente al auge de los medios de comunicación digital; esta importancia radica precisamente en el hecho de que muchas actividades comerciales y no comerciales que se realizan en la actualidad contemplan la utilización de dichas herramientas. El en el caso colombiano, a través de la ley 575 de 1999, se le brindó una normatividad al tema del comercio electrónico; dicha normatividad, aunque está vigente, ha traído consigo ciertas dificultades en la labor de los juristas al momento de legalizar o no un documento digital como prueba judicial dentro de un proceso.

El objetivo del presente trabajo es realizar un análisis de la normatividad colombiana en lo referente a la utilización de los documentos electrónicos como

* El artículo presenta resultados sobre la necesidad de la valoración probatoria de los documentos electrónicos en los procesos de carácter judicial. El texto es producto del ejercicio de Investigación desarrollado por los autores en el marco de la asignatura Metodología de la Investigación ( Asesores Javier Díaz Díaz, Matilde Gómez Bautista) de la Especialización en Derecho Procesal (Cohorte IV). Posgrados en Derecho. Universidad Santo Tomás Bucaramanga (Col). 
prueba dentro de los procesos contenciosos judiciales del Distrito Judicial de Bucaramanga, en las áreas del derecho civil, familia, administrativo y laboral.

Quienes tengan la oportunidad de leer el presente trabajo podrán entender que dentro de esta clase de pruebas no sólo se debe analizar los conocimientos básicos del derecho sustancial y procedimental, sino que, además, admitirán que están a tiempo de retroalimentar sus conocimientos, pero ya en esta ocasión dirigidos al campo electrónico, en aras de hacer, sin recelo alguno, mejores juicios de valor que le permitan razonar mejor las ventajas y desventajas cuando se ponen en la tarea de analizar y objetar las pruebas. Igualmente el lector podrá reflexionar acerca de la importancia de este recurso, el cual ha adquirido gran fuerza como forma de expresión del pensamiento y de la actividad humana, a tal punto que la vanguardia del conocimiento y del avance de la ciencia actual está vinculada principalmente a los documentos electrónicos.

\section{EL PROCESO Y LA PRUEBA COMO DOCUMENTOS DE VALOR PROBATORIO}

El derecho probatorio tiene un conjunto de reglas para darle el alcance que busca la figura jurídica dentro de los procesos o actuaciones donde se pretende demostrar los elementos de convicción; y allí, quedan comprendidas todas las clases de pruebas judiciales que tiene una determinada legislación, entre ellas, la prueba documental, la que ha sido definida por nuestra legislación colombiana, en su artículo 251 del Código del Procedimiento Civil, como

"los escritos, impresos, planos, dibujos, cuadros, fotografías, cintas
cinematográficas, discos, grabaciones magnetofónicas, radiografías,
talones, contraseñas, cupones, etiquetas, sellos y, en general, todo objeto
mueble que tenga carácter representativo o declarativo, y las inscripciones
en lápidas, monumentos, edificios o similares." (Henao, 2003, 96)

definición creada en un momento histórico en que los únicos soportes eran físicos, pero que ante los avances tecnológicos entra en crisis, sin que esto signifique que se dejen valorar bajo la perspectiva de un documento que tiene plena eficacia probatoria y relevancia en las etapas probatorias; en otras palabras, los documentos ya no son sólo una infinita combinación de átomos sino que también existen documentos conformados por BITS, lo que se ha denominado documento electrónico o, en los términos de la Ley 527 de 1999, mensaje de datos, por el cual se entiende:

«La información generada, enviada, recibida, almacenada o comunicada por medios electrónicos, ópticos o similares, como pudieran ser, entre otros, el intercambio electrónico de datos (EDI), Internet, el correo electrónico, el telegrama, el télex o el telefax". 
El término "proceso", derivado del latín "processus", tiene varios significados, entre ellos, progreso, avance, desarrollo, y otros, los cuales en el campo del derecho, emanan del conjunto de actividades que despliegan o desarrollan las partes integrantes de un litigio y que se llevan a cabo ante instituciones investidas de jurisdicción para que allí se estudien y armonicen todo un escenario de normas sustanciales y procesales que busquen la solución del conglomerado social. Al contextualizarlo dentro del campo jurídico existen muchas definiciones: Francesco Carnelutti, por ejemplo, define el "proceso" como

"el conjunto de actos coordinados y sucesivos realizados por los órganos investidos de jurisdicción y los demás sujetos que actúan a fin de obtener la aplicación de la ley sustancial o material a un caso concreto". (Camacho, 1993, 33)

Por su parte Gioseppe Chiovenda define el "proceso" como

"el conjunto de actos coordinados para la finalidad de la actuación de la voluntad concreta de la ley (en relación a un bien que se presenta como garantizado por ella) por parte de los órganos de la jurisdicción ordinaria." (Camacho, 1993,37);

y, a su vez, Rogelio Peña, afirma que el proceso jurídico se puede definir como:
"aquella estructura que surge como consecuencia de la unión creciente y ordenada de los diferentes actos procesales que se producen a través de la gestión de las partes, la cual obliga al representante del Estado, al terminar por disposición de la ley el acomodamiento, a dar respuesta con un pronunciamiento jurisdiccional a todas y cada una de las pretensiones, amparadas por la razón o no, hechas por la parte actora”. (Peña, 2004, 97).

Ahora bien, dentro de todo proceso judicial existe un elemento clave: la prueba. Al igual que en el caso del término "proceso ", el concepto de "prueba" se relaciona no sólo con el área del derecho, sino también de otras ciencias y de muchas actividades cotidianas. Tal y como lo afirma Hemel Hernández,

"la noción de prueba está presente en todas las manifestaciones de la vida humana y las distintas profesiones recurren a ella para demostrar o convencerse a sí mismos de la verdad de los hechos ocurridos en un pasado lejano o reciente" (Hernández, 2008, 1).

Ahora, la definición del término "prueba" desde el punto de vista jurídico tiene múltiples connotaciones, para el presente trabajo se hará referencia a tres de ellas, las cuales son más precisas en relación a las distintas corrientes del derecho. La primera hace referencia al trabajo de José Rodríguez Flórez sobre las pruebas judiciales, en el que sostiene que el derecho probatorio es el conjunto de reglas relativas al recaudo y valoración de los diversos medios que pueden emplearse para 
convencer al juez sobre los hechos de interés para el proceso. (Flórez, 2002, 26). Por su parte el profesor Gilberto Martínez, afirma que el concepto de prueba desde el punto de vista del procedimiento penal, es todo aquello que puede servir de convicción al funcionario para formarse un concepto con relación a los hechos ilícitos que se investigan y juzgan, con los autores o participes, con la responsabilidad de los mismos, con su personalidad y con los daños o perjuicios ocasionados. (Martínez, 1994, 375)

Finalmente, Hernando Devis define las pruebas judiciales como el conjunto de reglas que regulan la admisión, producción, atención y valoración de los diversos medios que pueden emplearse para llevar al juez la convicción sobre los hechos que interesan al proceso. (DEVIS, 2006, 25)

Así las cosas, la prueba judicial es algo complejo, que debido a esta situación debe evaluarse bajo ciertos principios que se relacionan a continuación:

1. El principio de la necesidad de la prueba y de la prohibición al aplicar el conocimiento privado del juez sobre los hechos, que alude a la necesidad de cualquier hecho sobre el cual debe fundamentare la sentencia, se encuentre acreditado con pruebas suministradas por cualquiera de los litigantes o por el órgano jurisdiccional, sin que el magistrado pueda cambiarla con el conocimiento personal privado que tenga sobre ellos.

2. La eficacia jurídica y legal de la prueba; significa que el juez debe considerar la prueba como el medio aceptado por el legislador para poder llegar, así, a una conclusión en lo referente a la existencia y modalidad de cualquier hecho afirmado.

3. La unidad de la prueba, el cual se fundamenta en la afirmación de que el conjunto probatorio del proceso forma una unidad y de esta forma debe ser examinado por el tribunal, al confrontar las diferentes pruebas (documentos, testimonios, y demás), señala su concordancia y discordancia y concluye sobre el convencimiento que de ellas se forme.

4. La comunidad o de la adquisición de la prueba, que se refiere al hecho de que la prueba debe tenerse en cuenta para determinar la existencia o inexistencia del hecho sobre el cual versa, ya sea que ésta resulte favorable a quien la propuso o al adversario, que bien puede invocarla.

5. El principio del interés público de la función de la prueba; aquí el objetivo de la prueba es crear la certeza en la mente del juez para que pueda decidir la "litis" conforme a la justicia; de ahí que se hable de un interés público en la función que desempeña en el proceso.

6. El Principio de la lealtad, probidad o veracidad de la prueba, que se basa en que la prueba no debe utilizarse nunca para deformar u ocultar la realidad.

7. La contradicción de la prueba, pues en todo proceso la parte contra quien se opone una prueba debe tener la oportunidad procesal no sólo de conocerla, sino también de discutirla, incluido incluso el derecho de contraprobar. 
8. El de igualdad de oportunidad para la prueba, el cual implica que los litigantes posean idénticas oportunidades para presentar pruebas o pedir la práctica; lo mismo que para contradecir las mismas propuestas por el adversario;

9. El Principio de publicidad de la prueba; el cual le permite a los litigantes tanto conocer las pruebas, como participar en su producción, impugnarlas, discutirlas y con posterioridad analizarlas en los respectivos alegatos para poner de relieve ante el órgano jurisdiccional el mérito que le asignan.

10. La formalidad y legitimidad de la prueba, en la que toda prueba debe estar revestida de requisitos extrínsecos: circunstancias de tiempo, modo y lugar; e intrínsecos: ausencia de vicios (dolo, error, violencia), y de inmoralidad en el medio mismo. La prueba debe provenir de quien se halle revestido de legitimidad para ofrecerla.

11. El de preclusión de la prueba, que busca evitar sorpresas a la contraparte con pruebas de último momento, que no se puedan controvertirlas o que sean referentes a cuestiones de las cuales no pueda ejercer su defensa.

12. La inmediación y de la dirección del juez en la producción de la prueba, este tiene como fin evitar que el debate se convierta en una lucha privada. Permite de la misma forma al juez la apreciación de la prueba; previéndolo de facultades para poder intervenir activamente en las propuestas por los litigantes.

13. La imparcialidad del juez en la dirección y apreciación de la prueba, este es un principio fundamental del derecho procesal. El siguiente es el principio de la originalidad de la prueba, que hace referencia a que la prueba debe referirse exclusivamente al hecho que ha de probarse.

14. La concentración de la prueba, donde la prueba debe practicarse en una misma etapa del proceso para evitar poner en peligro el respectivo cotejo y apreciación de la misma.

15. La libertad de la prueba, donde tanto las partes como el juez deben gozar de toda la libertad para lograr obtener todas las pruebas que sean pertinentes en el desarrollo del proceso.

De ahí que en aplicación a estos principios la prueba adquiere su relevancia jurídica y se torna en pilar fundamental del proceso, porque los hechos controvertidos dentro del mismo se incorporan y dilucidan a través de todos los medios probatorios que existen, los que buscan como fin u objetivo principal, llegar a la verdad de los hechos o al menos llegar a una proximidad posible con la exactitud de la realidad.

Ya evidenciados estos aspectos tan fundamentales en ámbito de ejercicio jurídico, se puede afirmar que la prueba es reconocida como el medio más confiable para descubrir la verdad real y, a la vez, la mayor garantía para evitar la arbitrariedad de las decisiones judiciales, ya que la búsqueda de la verdad sobre los hechos contenidos en una hipótesis acusatoria debe desarrollarse para llevar a la reconstrucción conceptual de aquellos. Tal y como afirma Alejandra Rivera: 
"La finalidad de la prueba judicial es la producción de la verdad es demostrar la verdad real o material, convencimiento psicológico del órgano judicial (juez). El principal propósito del proceso penal es la búsqueda de la verdad material para cuya consecución la ley de enjuiciamiento criminal establece los medios de prueba, basados en la valoración de la prueba y elaboración del veredicto." (Rivera, 2010, 1).

Además, conforme al sistema jurídico vigente en las resoluciones judiciales, sólo se podrá admitir como ocurridos los hechos o circunstancias que hayan sido acreditados mediante pruebas objetivas, lo cual impide que aquellas sean fundadas en elementos puramente subjetivos, la convicción de culpabilidad necesaria para condenar únicamente puede derivar de los datos probatorios legalmente incorporados al proceso; son las pruebas, no los jueces, las que condenan.

\section{LOS DOCUMENTOS ELECTRÓNICOS Y LOS REFERENTES NORMATIVOS EN COLOMBIA}

La prueba siempre ha tenido una gran importancia en todo acto que realice el ser humano, hasta el punto que ha sufrido transformaciones en el transcurso del tiempo de acuerdo al momento histórico en que se viva, con ella se solucionan los conflictos entre las partes, las que buscan como fin primordial acreditar los hechos y motivos que se han dado al interior de la controversia, y es por esto que el hombre ha aprovechado cualquier medio de prueba que le sirva para demostrar las afirmaciones en que recae su defensa, motivo por el cual se ha valido de los medios electrónicos, el desarrollo de la informática y de las telecomunicaciones, de tal manera que desde hace ya más de quince años se dispone de otros elementos documentales no convencionales que le permiten enriquecer su acerbo probatorio, lo cual permite consolidar avances importantes en el ámbito del Derecho.

Para nadie es un secreto que las nuevas tecnologías de la información han invadido todas las actividades, tanto públicas como privadas, de una sociedad que cada día se desarrolla más dentro del modelo de la globalización. Diariamente millones de documentos electrónicos, de carácter personal, comercial y/o gubernamental son enviados a través de las redes de Internet. Tal y como lo afirma Andrés Guzmán:

\footnotetext{
"Así como la tecnología, las comunicaciones y la ciencia avanza, las pruebas que se presentan en los procesos judiciales, van a la par, es innegable que hoy en día las transacciones comerciales, comunicaciones entre las personas, las relaciones laborales, las ofertas comerciales, los establecimientos de comercio, entre otros están migrando de un plano físico a un plano virtual.” (Guzman, 2011, 1)
}

Igualmente tampoco es desconocido para las nuevas generaciones y para las que han vivido la transición hacia la revolución informática, aceptar que "lo que no está 
en Internet no existe"; por ello no es equívoco afirmar que los funcionarios judiciales pasaron en su mayoría de la conocida máquina de escribir a los computadores para poder realizar su trabajo judicial, hasta el punto que si no tienen esta herramienta, le implica un desgate laboral y pérdida de tiempo.

Hoy el ciberespacio brinda múltiples oportunidades, la posibilidad de enviar mensajes y archivos adjuntos, junto con la escritura. Desde la invención del correo electrónico en 1971, hasta su desarrollo y expansión por intermedio de las redes sociales y los sistemas de telecomunicación, los nuevos documentos se generan por miles a lo largo y ancho del planeta y arrojan innumerables recursos probatorios al momento de requerir comprobar la veracidad de los hechos o de las palabras. Los documentos electrónicos revisten las características de ser uno más dentro de los documentos, $\mathrm{y}$, han nacido del gran auge que le ha dado, cada vez, el uso masificado de las tecnologías de la información, las telecomunicaciones y el comercio electrónico, lo que ha hecho que los países desarrollen un derecho más enfocado a la regulación normativa del uso de dichas tecnologías, e incluso han obligado a que la jurisprudencia se pronuncie para que fije los parámetros probatorios que se debe cumplir cuando de valorar pruebas que por este medio se presente en los asuntos litigiosos que son sometidos a valoración por parte de los contendientes; y es ahí, donde juega un papel importante el juzgador, porque se tiene que nutrir de conocimientos intrínsecos de carácter especial, que deben ir acompasados con la valoración de las pruebas y además remitirse a las normas que rigen sobre los documentos en general.

Asimismo, por las características especiales que reviste esta clase de documentos, se ha obligado al juzgador a que haga un mayor análisis del medio probatorio, porque debe tener en cuenta su autenticidad, su actor y la seguridad que la información suministra, de ahí que, del estudio ponderado que se le haga al documento electrónico depende el éxito y la eficacia que produce una prueba de carácter electrónico en un proceso contencioso; incluso se ha tenido referencia de ellos en las acciones supra-legales, donde han permitido demostrar la violación de derechos de carácter constitucional.

Por todas estas razones se ha generado la necesidad de crear una legislación que permita no sólo regular dicha actividad, sino que además permita validar como prueba dentro de un proceso judicial cualquier información digital. En el caso colombiano dicha normatividad se inició en el año 1995. El primer antecedente en la legislación colombiana en lo referente a los documentos digitales, se dio a través del Decreto 2150 de 1995; la finalidad de dicha legislación fue minimizar los trámites ante las entidades estatales y para lograr dicho propósito dispuso en su Art. 26 que:

"En la utilización de sistemas electrónicos de archivo y transmisión de datos las entidades de la administración pública deberán habilitar sistemas de transmisión electrónica de datos para que los usuarios envíen o reciban información requerida en sus actuaciones frente a la administración" 
Posteriormente, en el año 1999, se expidió el Decreto 1122, el cual contenía muchas disposiciones sobre el tema, pero fue declarado posteriormente inexequible por vicios de forma, mediante sentencia de la Corte Constitucional C-923/99. El Decreto consentía presentar peticiones, quejas o reclamaciones ante cualquier autoridad, vía mensajes de datos. Finalmente se expidió la ley 527 del 18 de agosto de 1999, la cual definió y reglamentó el acceso y el uso de los mensajes de datos del comercio electrónico y de las firmas digitales. También a través de esta ley se regularon todos los asuntos jurídicos relacionados con el comercio electrónico y limitó lo pertinente al reconocimiento de valor jurídico a los mensajes electrónicos de datos.

Los temas que regula la Ley 527 son entre otros: - Aplicación de los requisitos jurídicos de los mensajes de datos; - Comunicación de los mensajes de datos; Comercio electrónico en materia de transporte de mercancías; - Firmas digitales Certificados Digitales - Entidades de certificación - Suscriptores de firmas digitales - Funciones de la Superintendencia de Industria y Comercio. El principal objetivo de la Ley de Comercio Electrónico es adoptar un marco normativo que avale los desarrollos tecnológicos sobre seguridad en materia de comercio electrónico, de manera que se pueda dar pleno valor jurídico a los mensajes electrónicos de datos que hagan uso de esta tecnología.

En nuestro Sistema Judicial, ya la Corte Suprema de Justicia, Sala de Casación Civil, con ponencia del Dr. Pedro Octavio Munar mediante sentencia del 16 de diciembre de 2010, se pronunció para otorgar a los documentos electrónicos aptitud probatoria, y refiriéndose a los mensajes de datos refirió que de acuerdo a los postulados que revela el artículo 11 de la Ley 527, se debe atender las reglas de la sana crítica, que debe acompasarse con la confiabilidad que ofrezca el correo, es decir, la forma como se creó, igualmente acomete el estudio del archivo, comunicado del mensaje, su confiabilidad, conservación de la integridad de la información, su autor o cualquier otro componente relevante que se dé en esta clase de información y/o documentos.

Y con respecto a la firma digital para explicar que es la utilización de un certificado digital de los que venden las entidades de certificación digital, sostuvo que la firma electrónica se asemeja a la firma hológrafa, ya que tiene iguales funciones, pero que tiene más exigencias garantistas en técnicas de seguridad, porque no sólo

\footnotetext{
"se genera por medios que están bajo el exclusivo control del firmante, sino que puede estar avalada por un certificado digital reconocido, mecanismos que permiten identificar al firmante, detectar cualquier modificación del mensaje y mantener la confidencialidad de este" (Pedro Munar - Sentencia, 16 de diciembre de 2010).
}

Igualmente, la Corte Constitucional mediante Sentencia C-831 DE 2001, con ponencia del Doctor Álvaro Tafur Galvis, al referirse al tema de los documentos electrónicos hizo una exposición de lo que era el intercambio electrónico de datos e información, los mensajes de datos y su nivel de seguridad, la equivalencia de éstos 
con los escritos, y los requisitos para su validez en una actuación judicial. En aquel entonces, la Corte Constitucional se ciñó a examinar entre otros, si la aplicación de la ley 527 de 1999 se limitaba sólo al comercio electrónico o su aplicación era general para todos los mensajes de datos, para lo cual informó que el proyecto de ley colombiana tuvo como modelo, la ley de la Comisión de las Naciones Unidas para el desarrollo del Derecho Mercantil Internacional -CNUDMI- sobre Comercio Electrónico, y su iniciativa fue la del Ministerio de Justicia y con la participación de los Ministerios de Comercio Exterior, Transporte y Desarrollo, todo debido a las nuevos contextos en que se desarrollaban la comunicaciones y el comercio.

Sostuvo la Corte que, cuando se referían a los mensajes de datos, el mismo debía de recibir igual
"tratamiento de los documentos consignados en papel, es decir, debe dársele la misma eficacia jurídica, por cuanto el mensaje de datos comporta los mismos criterios de un documento",

puesto que dentro de sus características intrínsecas se evidencia que es una prueba que acredita la existencia y voluntad de las partes que se obligan, que documento es legible, hasta el punto que se pode almacenar e inmodificar, con la posibilidad de poderse revisar posteriormente para su ulterior consulta,

"es decir, que la información en forma de datos computarizados es susceptible de leerse e interpretarse".

De la misma forma rememoró el tema de las firmas digitales que tienen una clave secreta o privada y que lo que se busca es garantizar que el mensaje de datos viene de determinada persona, que no ha sido modificado desde su creación, transmisión y que el receptor no lo modificó. Y por último, hace referencia al valor probatorio de un mensaje de datos, para sostener que son confiables según la forma en la que se haya generado, archivado o comunicado el mensaje, y que su confiabilidad va a depender de la forma como se haya conservado la información en su integridad.

Asimismo, el estudio sobre el aporte y valoración de estos medios probatorios ha sido objeto de pronunciamiento por parte del Honorable Tribunal Superior de Bucaramanga, Sala Laboral, en la que acogió la tesis de la Corte Suprema de Justicia, y, al referirse al tema en un proceso de Acoso Laboral, mediante sentencia el 25 de junio de 2010, hizo un examen ponderado de la ilicitud de la obtención de una prueba de carácter electrónico, para llegar a la conclusión que:

"toda prueba obtenida con violación del debido proceso es nula también es aplicable a éste. De suerte que el debido proceso no lo reglamenta la Constitución sino la ley a través de los códigos procesales, es decir, que siempre que se omitan los parámetros legales establecidos para el procedimiento probatorio se está recaudando material probatorio constitucionalmente nulo, de ahí la importancia de recoger la prueba bajo los pedimentos normativos porque de no ser así, como ocurre en el caso de ataque, la prueba obtenida con violación a este principio no podrá ser tenida en cuenta." 
Es así que sin mayores esfuerzos, se puede afirmar que dada la importancia que la documentación digital ha tomado a nivel mundial en una sociedad globalizada como la actual, es fundamental que ésta sea reconocida como prueba en cualquier proceso judicial o administrativo que lo requiera. El correo electrónico y otras formas de comunicación catapultaron el uso de información electrónica de una manera inusitada, dejaron de ser temas teóricos para convertirse en temas cotidianos y comunes para todas las personas. Así mismo, transformaron la comunicación empresarial y personal al crear temas legales y éticos nuevos y retadores.

El uso de las pruebas electrónicas resulta algo novedoso en nuestro contexto y, por tal razón, ha sido complicado para aquellas personas que quieren hacer uso de ellas y no tienen el conocimiento propio de la seguridad jurídica de que goza un documento de esta clase, pues a pesar de que se cuenta con un régimen probatorio, soporte legal y pronunciamientos jurisprudenciales de las altas cortes, aún todavía se desconocen técnicas e instrumentos que permiten conocer los medios que existen en aras de constatar la veracidad de la información contenida en el documento electrónico, hecho que conlleva a que los jueces deban ser instruidos a través de máximo organismo de control, como es el que el Consejo Superior de la Judicatura, para que le suministren estrategias de inducción y capacitación que le haga más fácil la tarea a la cual se enfrentan constantemente en esta época.

\section{LA PRUEBA ELECTRÓNICA Y SU INCIDENCIA EN EL PROCESO JUDICIAL}

Los avances de la tecnología ha obligado al hombre a enfrentarse a un cambio en la forma de analizar las pruebas y valorarlas en un determinado proceso, hasta el punto que quien está de protagonista en el estudio de la prueba se ve en muchas ocasiones obligado a buscar la asesoría de un auxiliar de la justicia con el fin que le asegure el contenido real de la documental electrónica que se le presenta; sin embargo, este desconocimiento no es obstáculo para que al menos tenga la certeza de que un documento electrónico hace prueba plena si cuenta con la firma electrónica, lo que da lugar a que la contraparte deba demostrar su no autenticidad; caso contrario ocurre cuando el documento no contiene la firma electrónica, es entonces cuando el juzgador debe entrar a valorar la fiabilidad del sistema como fue generada esa prueba; y es allí, donde la Doctrina y la Jurisprudencia entra a jugar papel importante para trazar una serie de normas y reglas procesales sobre la valoración probatoria de estos documentos, empezar por tratar el tema de unificar en qué consiste la prueba electrónica y qué tipo de prueba se enfila en la prueba electrónica.

La novedad de la prueba electrónica ha hecho que las universidades enfoquen sus estudios en materia probatoria a esta clase de pruebas, a fin de facilitar a los futuros juzgadores unos conocimientos más óptimos y certeros cuando se enfrentan a la decisión de sus procesos judiciales, y no tener que dejar pasar por alto el análisis 
de algunos documentos que podían ayudar a esclarecer la Litis en controversia, que por el solo hecho de presentarse en medio electrónico y no tener los conocimientos mínimos en informática, y los referentes que ha fijado la Doctrina y la Jurisprudencia, han tenido que desconocer estos materiales probatorios, como sucede actualmente, que en muchas ocasiones por no conocer al menos lo que es un correo electrónico, se atemorizan de entrar en el análisis del mismo.

El tema de la información digital y su uso en los procesos judiciales como pruebas, se ha convertido en un gran reto para los países tanto desarrollados como tercermundistas. En estos últimos, como es el caso de Colombia, a pesar que se ha legislado respecto a este tema, aún existe confusión por parte de algunos legisladores que no permiten la aplicación de las leyes vigentes de la forma adecuada. Tal y como lo afirma Andrés Guzmán,

"es algo confuso para algunos juristas, la forma de presentar, solicitar y decretar pruebas, en las que existan archivos de datos, correos electrónicos, páginas de Internet, bases de datos, y en general información generada, enviada, recibida, almacenada o comunicada por medios electrónicos, ópticos o similares", (Guzmán, 2009, 1),

situación que permite afirmar que la regulación contenida en la ley 527 de 1999 , como la del Código de Procedimiento Civil, enfrentan al legislador, porque de una parte hay un régimen jurídico, particular y exclusivo para la prueba electrónica, y por la otra, porque el régimen jurídico existente debe adaptarse a las directrices de los medios electrónicos; pero el legislador en su sapiencia y al adoptar el criterio de su equivalente funcional, optó por cumplir los requisitos probatorios tradicionales cuando se trató de los mensajes de datos.

Repárese que la propia ley 527, en su artículo 11 dice que se necesitan algunas otras condiciones para que un documento electrónico se considere prueba judicial, hasta el punto que hace la claridad que debe
"tenerse en cuenta: la confiabilidad en la forma en la que se haya generado, archivado o comunicado el mensaje, la confiabilidad en la forma en que se haya conservado la integridad de la información, la forma en la que se identifique a su iniciador y cualquier otro factor pertinente.",

lo que indica que el juez puede negarle valor probatorio a un documento electrónico si considera que las condiciones tanto de su generación como de su transmisión y conservación del mismo no se consideran confiables. Pero nos preguntamos: ¿De qué forma entonces se debe presentar un documento electrónico para que tenga valor probatorio? La respuesta a este interrogante se encuentra en los artículos 6 a 10 de la citada ley y se puede resumir de la siguiente forma:

A) Debe constar por escrito: esto significa que deberá ser legible, sin importar el protocolo en el que esté, por ejemplo, tratándose de archivos de audio o video, aunque el protocolo, está diseñado para que los usuarios vean y escuchen, los archivos están 
escritos, en lenguaje máquina, que mediante un software convierte esto en imágenes o/y audio según sea el caso; sin olvidar que la información deberá estar disponible para su posterior consulta.

B) La Firma: el mensaje de datos deberá estar firmado, es decir, que deberá existir certeza de quién es su autor, esto puede ser, por ejemplo, en el caso de los correos electrónicos, con la dirección de e-mail o una dirección IP, entre otras o con una firma electrónica también regulada en la misma ley.

C) Original: la originalidad se refiere a que el archivo, deberá ser original, concepto distinto al que existe cuando se habla de originales y copias en papel, pues, por ejemplo, si la contabilidad de una empresa que es un archivo de Excel, está en el servidor de una empresa, debería llevar el servidor completo de la empresa, empero en realidad si se copia en una memoria extraíble o en $\mathrm{CD}$, se trata de una copia "digitalmente idéntica", por lo tanto, tendrá que ser tratada por el funcionario judicial como el original, es indispensable que quien realice las "copias" deje muy claro cómo las realizó, detalle fecha, hora, sistema operativo, actualizaciones o parches, software utilizado y, en general, todos los datos relevantes.

D) Integridad: es íntegro un mensaje de datos, si ha permanecido completa e inalteradamente, esto sólo se podrá garantizar si un notario certifica el contenido, fecha y hora de la toma, o se le coloca a la evidencia un certificado digital. En Colombia, CERTICÁMARAS es la entidad certificadora que puede prestar este servicio, las notarías están todas habilitadas, pero es de resaltar que la Notaría 76 del circuito de Bogotá a la fecha adelanta un plan piloto en manejo de evidencias para procesos judiciales. (Guzmán, 2009, 2)

Por otra parte, muchos juristas han criticado el artículo 6 de la ley 527, basándose en el hecho de que en él no se hace diferencia alguna entre información escrita y otros tipos de información, pero si se estudia con beneficio de inventario el contenido del artículo, el lenguaje jurídico que se usa cuando se habla de escrito, pueden considerarse también aquellos que se encuentran en formato digital, lo que hace que quede subsanado el supuesto equívoco.

Miller Rivera refiriéndose al tema, afirma que es indispensable distinguir un documento creado telemáticamente y aquel documento físico que ha sido guardado electrónicamente, porque si son de aquellos mensajes de datos que han sido creados y archivados por medios electrónicos, que tienen como fin ser trasmitido

“deberá ser de aquellos que hacen parte de los actos jurídicos no sometidos a requisitos especiales de creación (ad substantiam actus) o de prueba (ad probationem), caso en el cual deberá verificarse si se trata efectivamente de un "mensaje de datos"

propiamente dicho o de una "reproducción digital" de un documento per cartam, ello, afirma el autor, porque cada acto en la forma como se presente, se va a direccionar por distintos actos jurídicos, lo que implica que tenga un trato distinto en la legislación documental, tal como sucede con los documentos que deben ceñirse y cumplir los requisitos observados en el artículo 251 del Código de Procedimiento 
Civil, por tratarse de unos documentos de carácter representativo. (Rivera, 2008, 17).

Otro tema que se considera fuente de dificultad de muchos juristas en lo relativo a la aplicación de la ley 527 de 1999, es el equivalente funcional de original, citado en los artículos 8 y 9 de dicha ley, que dice:

Artículo $8^{\circ}$. Original. Cuando cualquier norma requiera que la información sea presentada y conservada en su forma original, ese requisito quedará satisfecho con un mensaje de datos, si: a) Existe alguna garantía confiable de que se ha conservado la integridad de la información, a partir del momento en que se generó por primera vez en su forma definitiva, como mensaje de datos o en alguna otra forma; b) De requerirse que la información sea presentada, si dicha información puede ser mostrada a la persona que se deba presentar. Lo dispuesto en este artículo se aplicará tanto si el requisito establecido en cualquier norma constituye una obligación, como si las normas simplemente prevén consecuencias en el caso de que la información no sea presentada o conservada en su forma original.

Aquí se puede apreciar que el concepto de original sufre una modificación dentro del contexto del comercio electrónico. Como se sabe en el contexto de la información digital, siempre se da una copia de la misma:

"Siempre se estará en presencia de una copia de la información. No puede identificarse un original, en este sentido, tal como se hace en los medios físicos tradicionales" (Riviera, 2008, 24).

En base a esto, el legislador estableció nuevos criterios al hablar del concepto "original" en los mensajes de datos. El legislador consciente de esta dificultad estableció nuevos criterios para determinar cuándo se está en presencia de un original en el contexto de los mensajes de datos. El literal "b" establece el requisito propio de todo escrito, al que ya se hizo referencia, de que la información pueda ser mostrada cuando se desea consultarla. Pero es el literal "a" el que establece una verdadera innovación, pues allí se estipula que se entenderá satisfecho el requisito de originalidad siempre que exista una garantía confiable de que la información se ha conservado íntegra desde el momento en que por primera vez se generó en su forma definitiva. Esto quiere decir que, en principio, cualquiera de las copias realizadas de un documento cualquiera podría ser considerado un original para efectos probatorios. Resultaría indiferente establecer cuántas copias se han realizado, o si el archivo electrónico que se examina es una copia de una copia o una copia del primer archivo que se creó. Así se habla de la llamada integridad de la información en el artículo $9^{\circ}$ que dice:

"Para efectos del artículo anterior, se considerará que la información consignada en un mensaje de datos es íntegra, si ésta ha permanecido completa e inalterada, salvo la adición de algún endoso o de algún cambio que sea inherente al proceso de comunicación, archivo o presentación. El grado 
de confiabilidad requerido, será determinado a la luz de los fines para los que se generó la información y de todas las circunstancias relevantes del caso.”

Cabe analizar otro hecho que en muchas ocasiones ocurre y es el que documentos físicos se conviertan por muchas causas en documento digitales. Según ley 527 no existe diferenciación a priori entre documentos físicos y digitales:

Otro elemento importante que debe destacarse es el hecho de que la información no requiere haber sido creada inicialmente en forma de mensaje de datos. Puede haberse creado en un soporte físico, y después haberse pasado a un formato digital. Este es una referencia verdaderamente innovadora de la ley 527, porque elimina de tajo cualquier diferenciación a priori que se quiera realizar entre los medios físicos y los medios electrónicos de transmisión y almacenamiento de información. No importa el soporte físico de la información, mientras se garantice que el traspaso de la información de un soporte a otro fue íntegro. No está de más resaltar que este concepto se aparta en buena medida de los conceptos tradicionales, como el que se encuentra en la ley 594 o ley general de archivos, la que en su artículo 3 define el documento original de la siguiente manera: Documento original. Es la fuente primaria de información con todos los rasgos y características que permiten garantizar su autenticidad e integridad. Por otra parte, vale la pena comparar este artículo con el artículo 261 del Código de Procedimiento Civil, que regula igualmente la integridad de la información de los documentos tradicionales:
"Los documentos rotos, raspados, o parcialmente destruidos, se apreciarán de acuerdo con las reglas de la sana crítica; las partes enmendadas o interlineadas se desecharán, a menos que las hubiere salvado bajo su firma quien suscribió o autorizó el documento."

Se aprecia claramente que el principio es esencialmente el mismo. Corresponde al juez determinar hasta qué punto los mecanismos electrónicos utilizados por las partes garantizaron la integridad de la información, y cuál es el verdadero riesgo de que la información haya sido verdaderamente alterada.

Finalmente hay que afirmar que es cierto que la finalidad de la ley 527 de 1999, fue dar las bases legales para normatizar todo lo concerniente al comercio electrónico, pero también lo es, que muchas de las dificultades que tienen los juzgadores al momento de conceder legalidad a un documento digital como prueba judicial, obedece a la falta de ilustración y conocimiento sobre las diferentes clases de documento que encajan en las pruebas electrónicas, tal como lo ha dispuesto la jurisprudencia, por lo tanto, se hace necesario implementar herramientas que permitan a los juzgadores retroalimentarse sobre el tema, para tener certero conocimiento sobre el mismo, para que de la conclusión que emita el funcionario, permita emitir fallos que correspondan a la realidad no sólo de los hechos sino de las pruebas que bajo estos parámetros se le han presentado a sus entes judiciales. 


\section{LA UTILIZACIÓN DE LA PRUEBA ELECTRÓNICA EN LOS PROCESOS CONTENCIOSOS DENTRO DEL ÁREA CIVIL, LABORAL, FAMILIA Y LA APLICACIÒN REALIZADA POR LOS JUECES DEL DISTRITO JUDICIAL DE BUCARAMANGA}

En muy pocos procesos de conocimiento de los jueces civiles, familia, laborales y administrativos de Bucaramanga, se han aportado documentos de carácter electrónico, y donde obran ellos, predominan los medios magnéticos de CD, seguido de los mensajes de datos o comúnmente llamados correos electrónicos y las grabaciones magnetofónicas; y muy escasos han sido los Despachos Judiciales que han fallado con fundamentos en esa clase de pruebas. Dentro del Círculo Judicial de Bucaramanga ha sido escaso el estudio de este moderno sistema de prueba, atendida la cantidad de despachos judiciales que existe actualmente, y quienes han emprendido la tarea, han hecho una operación lógica, al calificar no sólo de la prueba, sino que han armonizado los hechos en reciprocidad con las normas probatorias y con el conjunto racional del juicio han dictado sus fallos.

Transitar por este escenario no ha sido fácil para los juristas, ya que el auge de la informática en Colombia inicia en los años 80, época en que los juzgadores del Distrito Judicial de Bucaramanga apenas iniciaban sus estudios profesionales y las universidades no contaban con los equipos de informática que hoy tienen los nuevos estudiantes.

Sin lugar a dudas, en el mundo actual los medios digitales de información se han convertido en una de las principales herramientas del ámbito empresarial y laboral; diariamente miles de transacciones comerciales se realizan por estos medios; esto trae consigo que dentro de este contexto no se presenten conflictos o delitos que son castigados por la ley. Tal y como lo afirma Carmen Lázaro:

"Las tecnologías de información y la evolución de los sistemas de comunicación han transformado sustancialmente los procesos de intercambio y producción de información. No obstante, el uso masivo de los medios digitales no está exento de conflictos. Los delitos tradicionales han aprovechado estos nuevos canales de comunicación, dando lugar a nuevas categorías delictivas. Delincuentes y bandas organizadas han encontrado en los nuevos medios tecnológicos un firme aliado para la comisión de crímenes; tales como, la pornografía infantil a través de Internet, el phishing, el pharming, el abuso de medios corporativos y la competencia desleal, entre muchos otros. Frente a estas nuevas categorías de delitos de última generación, aparece una herramienta que permite demostrarlos ante la justicia: la prueba electrónica. Este instrumento está ganando cada vez más peso en los procesos judiciales; de tal forma, puede afirmarse que muchas pruebas tradicionales presentadas en juicio están migrando desde el soporte de papel hacia un entorno virtual, circunstancia que modifica, a su vez, los procesos de gestión y criterios de admisibilidad de las mismas en los procesos judiciales". (Lázaro, 2008, 140) 
En el actual mundo globalizado se está en presencia de innumerable información digital, por cualquier rincón se halla información de carácter electrónico, y en este contexto la doctrina probatoria y la jurisprudencia con sus recientes pronunciamientos ha dado pasos importantes para aceptar y reconocer que existen innovaciones probatorias que deben ir acompañadas con las herramientas procesales y sus procedimientos, de tal manera que se permita unificar la tarea de los jueces de la República en cuanto a la petición, decreto, práctica, aporte y valoración de material o pruebas electrónicas en los procesos contenciosos que se presenten al interior de los despachos judiciales.

Cuando se hace necesario entrar a hablar de la utilización de la prueba electrónica en los procesos judiciales, resulta importante enunciar todas aquellas reglas básicas que se deben seguir para lograr recaudar documentos electrónicos y que sean aceptados como pruebas dentro de cualquier proceso. Según Miller Rivera:

"Sea cual fuere la etapa o el medio probatorio por el cual se pretende allegar un documento electrónico al proceso judicial, la intervención del perito garantizará la inalterabilidad y la inmaculación necesarias para poder valorarlo en la sentencia o en el auto que le ponga fin a la actuación. De allí que sea necesario el planteamiento de protocolos especiales que garanticen su debido recaudo y análisis, pues como se ha demostrado, tan importante es determinar el valor que se le debe asignar a un documento como la identidad que éste tiene con el hecho alegado, en la medida en que se busca garantizar que el documento valorado es el mismo que se recaudó en la respectiva diligencia” (Rivera, 2008, 33).

De ahí que, para efecto de valorar una prueba de tipo electrónico es necesario que ella esté preexistida de inalterabilidad y la inmaculación protocolos especiales que garantizan que su recaudo y valoración se ha ceñido a ciertos requisitos y parámetros, que hacen que la prueba sea inalterable e inmodificable, tales como son la cadena de custodia y la copia bit a bit.

La Cadena de custodia, según Rodríguez F. Liliana es:

"el proceso documentado, aplicado por particular o servidor público, tendiente a demostrar la identidad, la originalidad e integridad de todo espacio o lugar considerado como escena o lugar de los hechos, así como de todo elemento desde su hallazgo, toma o recaudo, hasta que la autoridad judicial lo determine.” (Rodríguez, 2008, 60).

Lo que quiere decir que a través de este medio se garantiza con seguridad el contenido del documento, tal como la forma como fue almacenada, quién la recolectó, su procedencia y los motivos de quien la manejó y el por qué, además, es de vital importancia esta garantía de custodia, porque el juez cuando se pone en la tarea de hacer el estudio de las pruebas, puede confirmar y verificar la información allí contenida y estar seguro del lugar de los hechos, los protagonistas de los actos e 
incluso, determinar la autenticidad de la información que ella arroje.

Por otra parte la copia Bit a Bit, no es más que hacer una reproducción idéntica del documento que se pretende valorar, pues si se reproduce por otros medios como son los pantallazos, la impresión del contenido de sus archivos, esto puede ocasionar que se pierdan o atrofien datos reales del archivo. Un BIT se conoce en el medio de la informática como la unidad más pequeña de información que utiliza un ordenador. Esta sigla significa Binary Digit (Dígito Binario), que puede ser 0 ó 1 . Bits son varios dígitos, es decir varios Bit, por ejemplo, 10110; por último un Byte es la unión de 8 dígitos, es decir, 8 Bits son un Byte (Rivera, 2008, 36).

Suele presentarse que para este tipo de copias íntegras y universales, la información que allí repose, que generalmente es de un disco duro, debe ser por regla general documentos propios a la causa discutida en el proceso, pues si suele investigar archivos que no tiene relación con lo que se pretende probar, conllevaría a que se afectara la intimidad de quienes de una u otra forma han participado en la elaboración de esos documentos, y que para nada tienen relación con los hechos que se debaten.

Además de esos dos protocolos especiales, que valga recordar, son la inalterabilidad y la inmaculación de la prueba, existen otras reglas que el juzgador debe tener en cuenta al valorar las pruebas electrónicas, tales como el dictamen pericial y el peritaje que se hace sin inspección, incluso cuando ha sido objeto de tacha de falsedad e incidente de autenticidad, e igualmente cuando la prueba proviene de algunos informes o certificaciones, o la prueba en su defecto es trasladada, todo en virtud de garantizar el debido proceso a los contendientes y el derecho de contradicción, para obrar en aplicación a una sana crítica.

En efecto, cuando se trata de la Elaboración de un Dictamen, el perito tiene la obligación de certificar si se dio cumplimiento a las reglas de cadena de custodia, e inmediatamente proceder a rendir su concepto en un lenguaje que sea comprensivo para el juzgador, en el cual debe informar cual fue el diseño utilizado en la prueba, la metodología de extracción, la técnica de análisis, el estado del arte en ingeniería forense y las conclusiones del perito.

El juez Colombiano que pretenda hacer uso de esta herramienta procesal, podrá acudir a ACIS (Asociación Colombiana de Ingenieros de Sistemas), que es la entidad que está encomendada de fijar y establecer las normas de procedimiento de investigación frente a documentos electrónicos. Dicha entidad se encarga hacer estudios de temas intrínsecos a los documentos electrónicos, tales como verificar la fecha de su creación, de modificación, el tipo de formato, del tamaño del documento electrónico, e igualmente, de identificar quién fue su creador y receptor y si fue o no encriptado, lo que permite comprobar la seguridad del mismo. Ahora, cuando se trata de esos Peritajes sin inspección, se debe tener en cuenta las reglas que se señalaron anteriormente, salvo las relativas a la intervención del juez, porque éste está en la facultad de acudir al perito si así lo estima conveniente en aras de conceptos más técnicos. 
Por otra parte, no se puede desconocer que los documentos electrónicos como cualquier otro documento de tipo gráfico, pueden ser objeto de Tacha de falsedad e incidente de autenticidad, casos en los cuales se debe acudir al respectivo incidente consagrado en el artículo 139 del Código de Procedimiento Civil, y seguir con los parámetros allí señalados, de tal manera que a las pruebas electrónicas se le dará el mismo trato de las pruebas que no lo son. Igualmente, cuando se realiza el estudio de las pruebas de documentos de carácter público, de acuerdo con lo previsto en el artículo 264 ibídem, tales documentos se entiende que fueron expedidos por funcionarios competentes para ello, tal es el caso de aquellos que expiden los registradores de instrumentos públicos, los notarios y otros funcionarios estatales, lo que implica que dan fe de su otorgamiento y declaración de lo que allí se contiene, pero si el documento está impregnado de vicios, serán objeto de tacha como anteriormente se dijo.

Por último, en cuanto a la Prueba trasladada, se puede dar el caso que el documento electrónico repose en otro proceso donde fue recolectado válidamente, ahí, es cuando se puede hacer uso de las copias bit a bit, documentos o pruebas que se piden en la misma forma para la producción de la prueba que ha previsto la legislación procesal, en la cual no puede dejarse de lado las estrictas normas de la cadena de custodia, siempre que en el nuevo proceso se garantice su conducencia, su pertinencia y utilidad, así como su legalidad y su licitud.

En lo referente a la valoración de un documento digital como prueba, sólo podrá ser hecha por un juez, el cual deberá determinar tres aspectos fundamentales de la prueba: la calidad de la información, la fuente y el contenido. En cuanto a la utilización de la prueba electrónica en Colombia, cabe destacar que precisamente por las causas nombradas en el capítulo III del presente trabajo, aún es mucho el trabajo que se debe hacer por parte de los entes judiciales para lograr que los documentos digitales sean considerados como pruebas dentro de cualquier proceso judicial.

Ahora, para que un documento digital sea aprobado como prueba judicial dentro del desarrollo de un proceso, se hace necesario por parte de los peritos llevar a cabo un protocolo. Dicho protocolo será aprobado por el juez del caso al determinar los tres aspectos fundamentales de la prueba.

\section{CONCLUSIONES Y RECOMENDACIONES}

Se tiene establecido que en todo juicio la prueba es reconocida como el medio más confiable para descubrir la verdad real y, a la vez, la mayor garantía para evitar la arbitrariedad de las decisiones judiciales. Ya que la búsqueda de la verdad sobre los hechos contenidos en una hipótesis acusatoria debe desarrollarse para llevar a la reconstrucción conceptual de aquellos. Tal y como afirma Alejandra Rivera:

"La prueba se convierte en el medio más seguro de lograr dicha reconstrucción de modo comprobable y demostrable, pues la inducirá de los rastros o 
huellas de los hechos que pudieron perimentaciones o de inferencia sobre aquello. Además, conforme al sistema jurídico vigente en las resoluciones judiciales sólo se podrá admitir como ocurridos los hechos o circunstancias que hayan sido acreditados mediante pruebas objetivas, lo cual impide que aquellas sean fundadas en elementos puramente subjetivos, la convicción de culpabilidad necesaria para condenar únicamente puede derivar de los datos probatorios legalmente incorporados al proceso, son las pruebas no los jueces, las que condenan, ésta es la garantía, la prueba por ser insustituible como fundamento de una condena es la mayor garantía frente a la arbitrariedad punitiva". (Rivera, 2010, 1)

Dada la importancia que la documentación digital ha tomado a nivel mundial en una sociedad globalizada como la actual, se hace necesario que esta sea reconocida como prueba en cualquier proceso judicial o administrativo que lo requiera. El correo electrónico y otras formas de comunicación catapultaron el uso de información electrónica de una manera inusitada, dejan de ser temas teóricos para convertirse en temas cotidianos y comunes para todas las personas. Así mismo, transformaron la comunicación empresarial y personal crearon temas legales y éticos nuevos y retadores, hasta el punto que cualquiera con un conocimiento elemental de informática sabe que una impresión de un correo electrónico no garantiza la autenticidad real del documento.

Se pudo comprobar que la finalidad de la ley 527 de 1999, fue dar las bases legales para normatizar todo lo concerniente al comercio electrónico, aún hoy son muchas las dificultades que tienen los juristas al momento de conceder legalidad a un documento digital como prueba judicial; se hace necesario con urgencia, implementar herramientas que les permitan a los entes judiciales poder homologar el concepto de prueba judicial desde el punto de vista de los documentos digitales.

Igualmente se determinó dentro del presente trabajo que para que un documento digital sea aprobado como prueba judicial dentro del desarrollo de un proceso, se hace necesario por parte de los peritos llevar a cabo un protocolo; dicho protocolo será aprobado por el juez del caso al determinar los tres aspectos fundamentales de la prueba: calidad de la información, la fuente y el contenido.

La investigación demostró que cuando se trata de valorar pruebas de carácter electrónicas, se generan de inmediato dificultades para el que pretende utilizarlas, todo debido a la escasa capacitación técnica de las partes del proceso, e incluso a buena parte de los juzgadores, porque cuando se proponen a la tarea de discernir los planteamientos técnicos de las pruebas que se le presentan por los diferentes medios electrónicos, suelen desconocer los requisitos que se han de tener en cuenta en su valoración, e incluso se desconoce que existe legislación especial sobre el tema, y un pronunciamiento de la Corte Suprema de Justicia Sala de Casación Civil, que ha trazado los parámetros sobre los requisitos que se deben tener en cuenta cuando de tomar una decisión con fundamento en una prueba de este tipo. 
Se constató a lo largo de la investigación que la novedad de las pruebas electrónicas ha generado problemas para quien pretende utilizarlas y no tiene el más mínimo conocimiento sobre las mismas, todo debido a su escasa capacitación técnica de buena parte de los protagonistas de un proceso, y más cuando éstos son personas mayores adultas que no tuvieron la oportunidad en sus claustros universitarios de tener acceso al mundo informático que le permitiera en el día de hoy contradecir con propiedad los planteamientos técnicos que le presentan las partes, los testigos e incluso los peritos.

De lo dicho a lo largo de la investigación se puede concluir que la seguridad jurídica de que goza un documento electrónico depende en cierta medida de que el destinatario que va hacer uso de ella no sea ajeno a la incuestionable realidad del mundo informático que actualmente se vive, para que no se desplace o sea desplazado cuando pretende hacer uso de estos documentos electrónicos, ya sea como juzgador o como destinatario que va a tener de alguna $u$ otra manera productividad en la misma.

Se evidenció a lo largo de la investigación que la utilización de la prueba electrónica, innegablemente debe ir precedida de una cadena de custodia que ofrezcan motivos de seguridad, que permitan a los funcionarios judiciales encargados de aplicarla o, en su defecto, valorarla, hacer elocuciones respecto a ella, cuando se disponen plasmarlas al caso concreto. Igualmente se observó cómo nuestro régimen probatorio colombiano a través de las diferentes normas y pronunciamientos jurisprudenciales, cuenta con un soporte jurídico que permite la valoración y aceptación de la prueba electrónica; pero al interior de ésta Colombia, se evidenció que existe otra realidad, cuando se evidencia que no es mucho el avance sobre el tema de los documentos electrónicos en comparación de otros países, como tampoco que haya sido fácil la implementación y uso de medios tecnológicos en grado de avanzados dentro de los estrados judiciales, hasta el punto que se pudo evidenciar que existen juzgadores que no cuentan con los elementos necesarios, al menos para que por su propia cuenta utilicen métodos innovadores y prácticos.

De acuerdo a las encuestas que se realizaron dentro del Distrito Judicial de Bucaramanga, y al haberse establecido que en la práctica judicial es mucho lo que se desconoce sobre las técnicas e instrumentos que permiten rectificar la veracidad de la información contenida en el documento electrónico, se recomienda que desde las universidades perfilen e instruyan a sus estudiantes quienes son los futuros juzgadores, en temas transcendentales que actualmente nos proliferan en este mundo globalizado de las comunicaciones, a fin de que aprendan a examinar y analizar las pruebas electrónicas que actualmente abundan; igualmente se recomienda que por parte de las entidades que manejan el funcionamiento de los órganos judiciales como es el Consejo Superior de la Judicatura, propongan y realicen actividades para los juzgadores actuales que no tuvieron la oportunidad de ser formados bajo el mundo informático y de esta manera puedan tener mayor certeza en sus conocimientos cuando los van a aplicar en las actividades de análisis probatorio. Igualmente se suplica que el Consejo Superior reglamente y capacite a todos sus empleados o personas que tiene 
a su servicio, a fin de retroalimentarle sus conocimientos en materia tecnológica, para que en cualquier momento en cumplimiento de sus funciones puedan utilizarlas y afrontarse a las novedades que le brinda la informática.

Por último, y por estar en manos de nuestros legisladores la suerte de las normatividades, se suplica que por parte del Congreso se profiera con urgencia una nueva ley que desde ya señale los parámetros y requisitos que debe cumplir el documento electrónico, y no dejar que su valor probatorio dependa de las exposiciones hechas por la doctrina o jurisprudencia.

\section{REFERENCIAS}

Azula Camacho, Jaime. (1993) Manual de Derecho Procesal Civil, Tomo I, Teoría General del Proceso, Cuarta Edición, Editorial Temis S.A., pp. 33, 35

Devis, Hernando. (2006) Teoría General de la Prueba Judicial. Editorial Temis p. 25. Flórez, José. (2002). Pruebas Judiciales. Biblioteca jurídica Dike. P. 26.

Hernández, Hemel. (2008). Pruebas Judiciales. Tecnológico de Antioquia, p. 1. Henao, Óscar. (2003). Código de Procedimiento Civil. Editorial Leyer, p. 96.

Peña, Rogelio. (2004). Teoría General del Proceso. Editorial Temis. p. 97.

Rodríguez, Liliana, (2008) "Diplomado sobre el nuevo sistema de cadena de custodia”, en Plan Nacional de Capacitación, T. II. Bogotá, Sistema Nacional de Defensoría Pública, 2008. P. 60.

\section{Páginas Web}

Guzmán, Andrés. (2009) ¿cómo se presentan pruebas judiciales sobre mensajes de datos? Recuperado de p://www.adalidabogados. com/Pruebas $\% 20$ Judiciales\%20Sobre\%20Mensajes\%20de\%20Datos.pdf. P.1

Lázaro, Carmen. (2008). Pruebas electrónicas ante los tribunales en la lucha contra la cibercriminalidad. Un proyecto europeo. Recuperado de: http://www.scielo. org.ve/scielo.php?pid=S1690-75152008000200009\&script $=$ sci_arttext. P. 140

Martínez, Gilberto. (1994). Código de Procedimiento Penal. Editorial Temis Recuperado de: http://issuu.com/ngiraldo/docs/ pruebasjudiciales. P. 375.

Rivera, Alejandra. (2010).Finalidad de la Prueba Judicial. Recuperado de: http:// es.scribd.com/doc/34939977/Prueba-Judicial. P.1.

Rivera, Miller. (2008) El Manejo del documento electrónico y su regulación en las distintas etapas del íter probatorio en el proceso civil. Fundación Universitaria San Martín. Recuperado de: http://nisimblat.net/universidad/ponenciacongreso. html. pp. 17 y 24. 


\section{Legislación}

Constitución Política de Colombia.1991.

Ley 794 de 2003. Por la cual se modifica el Código de Procedimiento Civil, se regula el proceso ejecutivo y se dictan otras disposiciones.

Código de Procedimiento Civil.

Ley 527 de 1999, Ley de Comercio Electrónico

\section{Jurisprudencia}

Auto 13015 de la Sala de Casación Laboral de la Corte Suprema de Justicia.

Auto del 7 de abril de 2000 de la Sala de Casación Civil y Agraria de la Corte Suprema de Justicia.

Sentencia Corte Suprema de Justicia. Sala Laboral. 13015 de Abril 3 de 2000. Magistrado Ponente: José Roberto Herrera Vergara.

Sentencia Sala De Casación Civil, magistrado ponente Pedro Octavio Munar Cadena.

Bogotá, D.C., dieciséis (16) de diciembre de dos mil diez (2010)

Sentencia C-798 de 2003 de la Corte Constitucional

Sentencia C-662 de 2000 de la Corte Constitucional

Sentencia C-831 de 2001 de la Corte Constitucional

Sentencia Sala Laboral, magistrado ponente Henry Lozada Pinilla. Bucaramanga, Veinticinco (25) de junio de dos mil diez (2010). 


\section{APÉNDICES}

\section{Apéndice 1. Encuesta aplicada \\ a funcionarios judiciales (formato)}

\section{ENCUESTA}

La presente encuesta tiene como objetivo académico obtener información estadística, si los funcionarios judiciales del Distrito Judicial de Bucaramanga, le dan valor probatorio intrínseco a los documentos electrónicos como pruebas válidamente solicitadas, decretadas y practicadas y su incidencia en los fallos definitivos, por lo tanto, solicitamos colaboración en la respuesta de la misma.

\section{FUNCIONARIOS RAMA JUDICIAL 2011}

\section{APLICACIÓN DEL DOCUMENTO ELECTRÓNICO EN LOS PROCESOS JUDICIALES}

Distrito Judicial:

Despacho Judicial:

Cargo:

1. ¿TIENE USTED CONOCIMIENTO EN INFORMÁTICA?.

SI

NO

2. COMO JUEZ, ¿TIENE USTED PROCESOS, DONDE SE HALLAN PRUEBAS ELECTRÓNICAS?

SI $\mathrm{NO}$

Qué cantidad:

Tipos de procesos:

Ordinarios Ejecutivos Verbales Sumarios

Abreviados Otros Cuáles

Que jurisdicción?

Laboral Familia Penal Civil

Administrativa Otros Cuáles 
3. ¿EN QUÉ CANTIDAD DE PROCESOS, APROXIMADAMENTE, USTED HA DECRETADO ESTA MODALIDAD DE PRUEBAS?
a) De 0 procesos.
B) 1 a 5
c) 5 a 10
d) 10 a 15
c) 15 a 20
d) más de 20 .

4. LAS PRUEBAS ELECTRÓNICAS SOLICITADAS Y DECRETADAS, SON CONTROVERTIDAS POR LAS PARTES?.

SI $\mathrm{NO}$

5. ¿TIENE USTED COMO JUEZENCUENTA LA PRUEBA ELECTRÓNICA SOLICITADA, DECRETADA Y PRACTICADA EN EL PROCESO JUDICIAL PARA DICTAR LA DECISIÓN QUE DE FONDO TOME? SI $\mathrm{NO}$

6. ¿QUIÉN PRACTICA EN SU DESPACHO LAS PRUEBAS ELECTRÓNICAS?
a) El Mismo Funcionario o fallador
b) El Auxiliar de la Justicia
c) Los empleados del despacho
d) Otro
Cuál

7. ¿QUIÉN ANALIZA LA PRUEBA ELECTRÓNICA?
a) El Juez
b) Los empleados del Juzgado
c) El auxiliar de la Justicia
d) Otro
Cuál

8. AL MOMENTO DE TENER EN CUENTA LA PRUEBA ELECTRÓNICA PARA DICTAR UN FALLO CON FUNDAMENTO EN LA MISMA, USTED: ¿A QUIÉN RECURRE?
a) A sus conocimientos
b) Auxiliar de la justicia.
c) Empleados del Juzgado
d) A la controversia de las partes

9. ¿CUÁL ES EL CRITERIO QUE TIENE USTED PARA DARLE VALOR PROBATORIO A LAS PRUEBAS ELECTRÓNICAS?
a) Filosófico
b) Jurídico
c) Técnico
d) Precedentes Jurisprudenciales
e)Otros.Cuáles 
10. ¿EL VALOR PROBATORIO DEL DOCUMENTO ELECTRÓNICO DEBE SER EL MISMO QUE SE LE DA A OTRAS PRUEBAS DOCUMENTALES?

$\mathrm{SI}$ NO Por qué:

Gráfico 1. Muestra de lo que es un pantallazo

Se observa en la presente figura, el escritorio de un computador, en el que se evidencia varios elementos gráficos conocidos como iconos, ventana, menús y cajas de diálogos. Herramientas que nos van a permitir ver las carpetas y archivos almacenados, como las fechas de su creación, modificación y eliminación. Datos estos de vital importancia porque de ahí el éxito cuando se valora una prueba que ha sido obtenida a través de este medio.

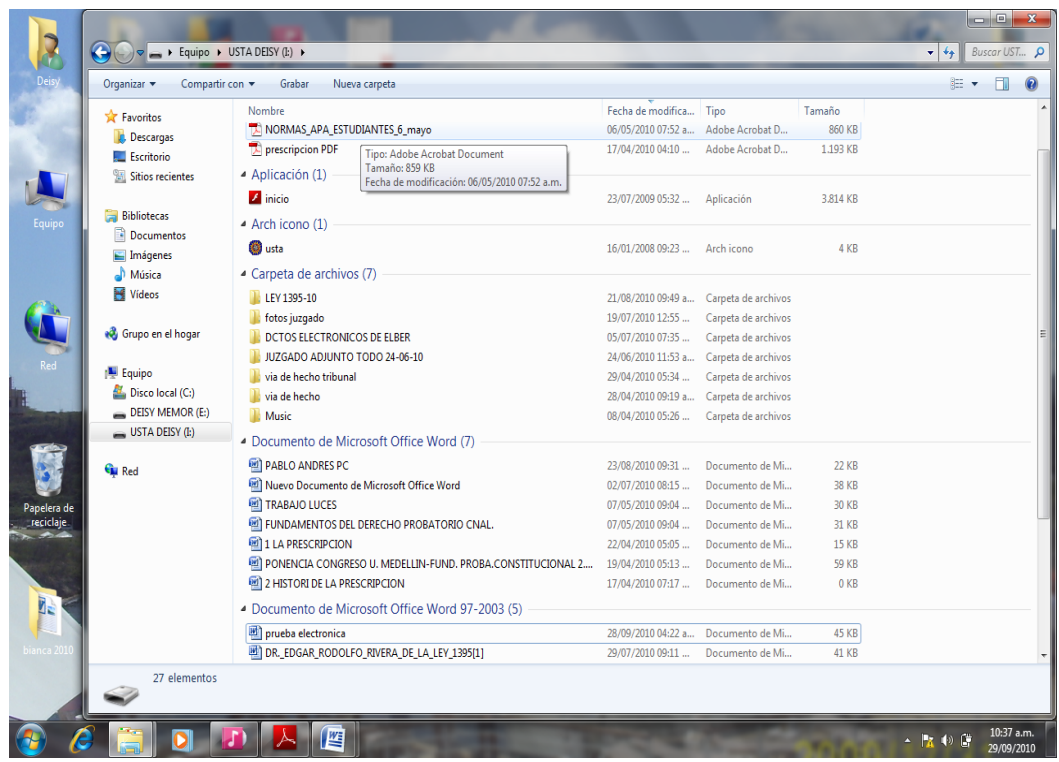

Gráfico 2.

Las pocas pruebas electrónicas que se han tenido en cuenta para fallar procesos contenciosos del derecho civil, laboral, familia y los especiales de acoso laboral los podernos sintetizar así: 


\section{TRIBUNAL SUPERIOR DE BUCARAMANGA}

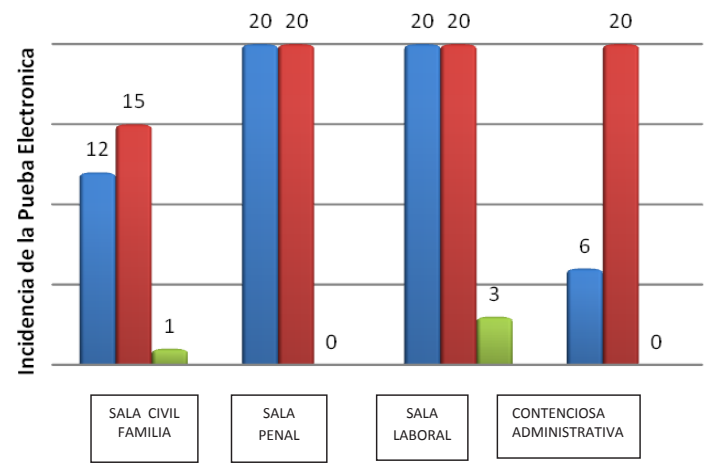

I HAN ESTUDIADO LA PRUEBA ELECTRONICA

$\square$ LE HAN APORTADO PRUEBA ELECTRONICA

$\square$ HA FALLADO CON UNA PRUEBA ELECTRONICA

TRIBUNAL CONTENCIOSO ADMINISTRATIVO

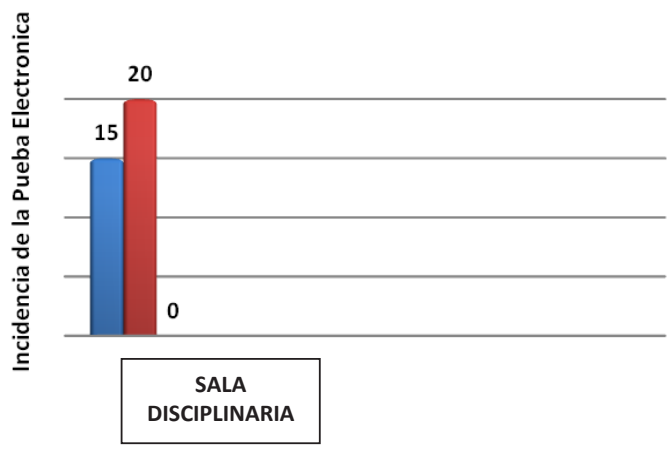

$\square$ HAN ESTUDIADO LA PRUEBA ELECTRONICA

- LE HAN APORTADO PRUEBAS ELECTRONICAS

$\square$ HAN FALLADO CON PRUEBA ELECTRONICA 

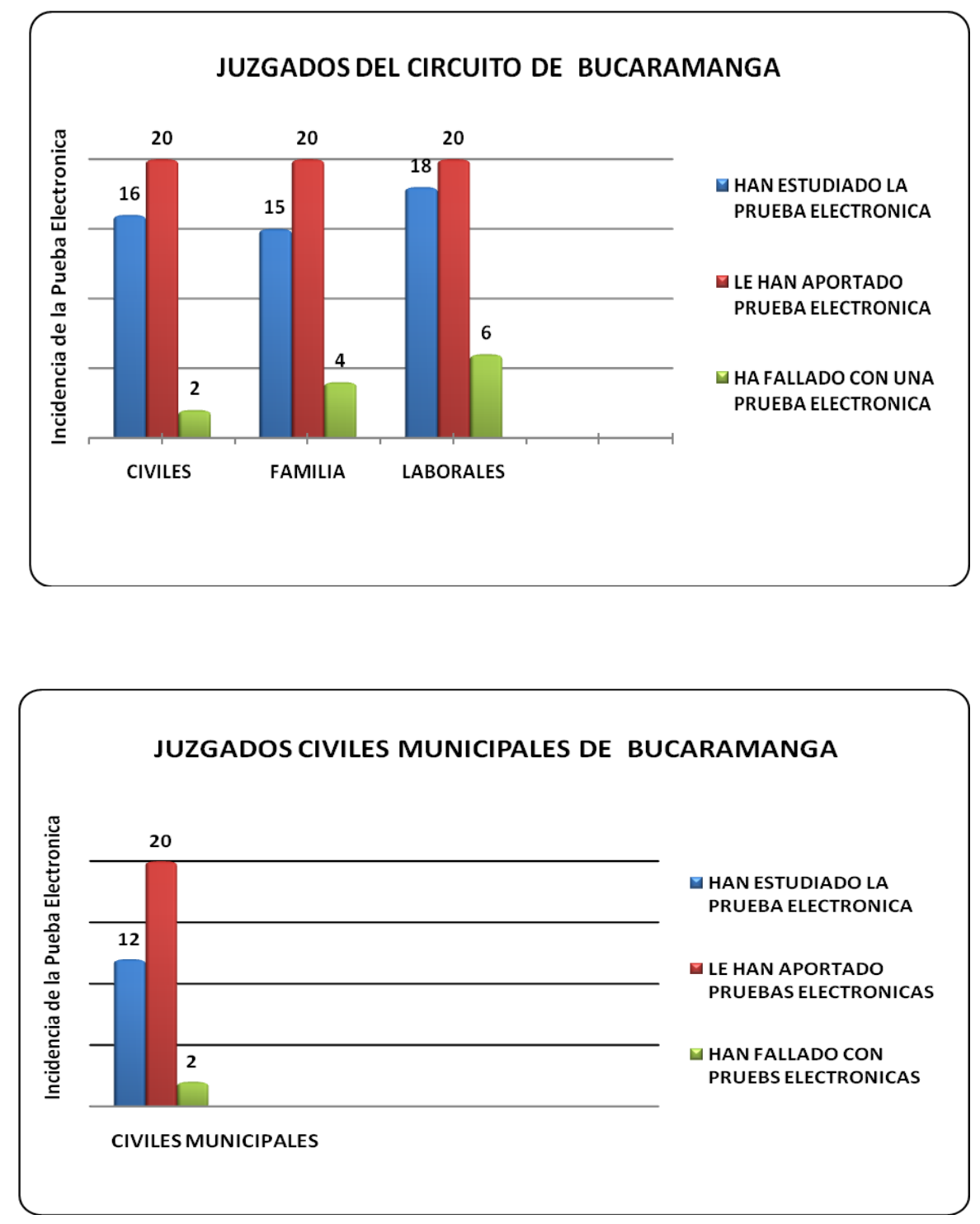